\title{
ASPECTOS HISTOLÓGICOS DO APARELHO REPRODUTOR FEMININO E MORFOMETRIA DOS OVÁRIOS DE TROPIDACRIS COLLARIS (STOLL, 1813) (ORTHOPTERA: ROMALEIDAE) SUBMETIDO A TRÊS FOTOPERÍODOS
}

\section{F.D. Santos ${ }^{1}$, A.F.S.L. Veiga ${ }^{1}$, L.C. Alves ${ }^{2}$, V. Wanderley-Teixeira ${ }^{1}$, A.A.C. Teixeira ${ }^{3}$}

${ }^{1}$ Universidade Federal Rural de Pernambuco, Departamento de Agronomia, Rua Dom Manoel de Medeiros, s/ no, CEP 52171-900, Recife, PE, Brasil. E-mail: tatefabi@ig.com.br

\section{RESUMO}

\begin{abstract}
A pesquisa teve o objetivo de descrever a histologia dos ovários, ovidutos laterais, oviduto comum e espermateca, e realizar a morfometria dos ovários de Tropidacris collaris (Stoll, 1813) (Orthoptera: Romaleidae), submetido aos fotoperíodos de 10L:14E, 12L:12E e 14L:10E. Para morfometria utilizou-se uma lupa binocular adaptada com uma ocular milimétrica, sendo registrado o comprimento e as larguras dos ovários. Posteriormente, os ovaríolos foram separados e contados. Para análise histológica, os órgãos foram fixados em Boüin alcoólico, incluídos em "paraplast" e corados pela H.E., tricrômico de Mallory e P.A.S (Ácido Periódico de Schiff). Os resultados mostraram que não houve influência dos fotoperíodos sobre a morfometria dos ovários, número de ovaríolos e histologia dos órgãos. Foram encontrados ovários préreprodutivos e reprodutivos. As médias do número de ovaríolos foram de 195,62, 202,62 e 208,25 para os fotoperíodos de 10L:14E, 12L:12E e 14L:10E, respectivamente, sendo mais numerosos no ovário esquerdo. Cada ovaríolo apresentou morfologia tubular com regiões bem distintas (filamento terminal, germário e vitelário). O oviduto lateral é revestido internamente por tecido epitelial simples cúbico com numerosas dobras, apoiado no tecido conjuntivo e externamente por uma camada de tecido muscular estriado. $\mathrm{O}$ oviduto comum apresenta a mesma constituição histológica do oviduto lateral, exceto pela presença de epitélio com íntima cuticular e uma camada muscular bem desenvolvida. A espermateca é constituída por tecido epitelial pseudo-estratificado colunar com íntima cuticular e tecido muscular estriado associado a tecido conjuntivo.
\end{abstract}

PALAVRAS-CHAVE: Tropidacris collaris, histologia, aparelho reprodutor feminino, morfometria.

\section{ABSTRACT}

HISTOLOGICALASPECTSOFTHEFEMALEREPRODUCTIVESYSTEMANDMORPHOMETRY OF THE OVARIES OF TROPIDACRIS COLLARIS (STOLL, 1813) (ORTHOPTERA: ROMALEIDAE) SUBMITED TO THREE PHOTOPERIODS. The research aimed to study the histology of ovaries, lateral oviducts, common oviducts and spermatheca, and morphometry of the ovaries of Tropidacris collaris (Stoll, 1813) (Orthoptera: Romaleidae), reared under the photoperiods 10:14, 12:12 and 14:10 (L:D). Morphometry was conducted using a binocular magnifying glass adapted with a milimetric ocular, being registered the length and the width of the ovaries. Subsequently the ovarioles were separated and counted. For the histological analysis, the organs were fixated in alcoholic Boüin, included in "paraplast" and stained by H.E., Mallory's trichromic and P.A.S. Photoperiods studied did not influence the morphometry of the ovaries, number of ovarioles and the histology of the organs. The averages of the ovarioles number were of 195,62, 202,62 and 208,25 for the fotoperíodos of 10L:14D, 12L:12D and 14L:10D, respectively, being more numerous in the left-side ovary. Each ovarioles presented tubular morphology with distinct regions (terminal filament, germarium and vitellarium). The lateral oviducts are internally covered by simple cubic epithelial tissue with numerous folds, sustained on the connective tissue and, externally, by a striated muscular tissue layer. The common oviduct presents the same histological constitution of the lateral oviduct, except by the presence of the epithelium with cuticular intima and a well

${ }^{2}$ Universidade Federal Rural de Pernambuco, CPqAM-FIOCRUZ, Recife, PE, Brasil.

${ }^{3}$ Universidade Federal Rural de Pernambuco, Departamento de Morfologia e Fisiologia Animal, Área de Histologia, Recife, PE, Brasil. 
developed muscular layer. The spermatheca is constituted by columnar pseudo-stratified epithelial tissue with cuticular intima and striated muscular tissue associated to connective tissue.

KEY WORDS: Tropidacris collaris, histology, female reproductive system, morphometry

\section{INTRODUÇÃO}

Dentre as espécies de gafanhoto, o Tropidacris collaris (Stoll, 1813) (Orthoptera: Romaleidae) chama atenção pelo seu grande tamanho, cujo comprimento varia de 50 a $70 \mathrm{~mm}$ para o macho e 85 a $105 \mathrm{~mm}$ para afêmea, sendoconsiderada uma espécie deimportância econômica (D'Araújo et al., 1968; SANTOS, 1982; Duranton et al.,1987; C hagas et al.,1995; COSTA, 2003).

No aparelho reprodutor dos ortópteros há um par de ovários, constituídos por um número variável de ovaríolos do tipo panoístico, ou seja, desprovidos de células nutridoras dos oócitos. Os ovaríolos ligam-se aos ovidutos laterais, os quais se unem formando o oviduto comum conectam-se à câmara genital, onde também se abre o ducto da espermateca (UvAROV, 1966; Silva \& CAETANO, 1991).

Estudos morfológicos e histológicos do aparelho reprodutor feminino têm sido relatados por vários autores como importante instrumento para relações filogenéticas entre as espécies de insetos (LaLITHA et al.,1997; B ILINSK etal.,1998; J AGLARZ,1998; KUBRAKIEWICZ et al., 1998; SimicZYJeWet al., 1998; SZKLARZEWICZ, 1998). Silva \& CAETANO (1991) relatam ainda que o aparelho reprodutor feminino de Orthoptera, em particular de Acrididae, tem sido discutido em termos comparativos por muitos autores, encontrando-se acentuadas variações morfológicas. De acordo comJAGLARz(1998) o número de ovaríolos por ovário é variável e mostra diferenças interespecíficas. Segundo MATSUDA (1976) o número de ovaríolos pode decrescer em alguns grupos de orthoptera, podendo chegar a cinco ovaríolos por ovário em Acrididae.

DuRANTON etal. (1987) estudandogafanhotos sugerem ainda a morfometria para comparar espécimes em uma mesma população mesmo esta sendo fisionomicamente homogênea, pois os estudos morfométricos além da caracterização de fases (polimorfismo), podem servir igualmente para estudar a mistura de duas populações de origem diferentes em um mesmo local e colocar em evidência as variações geográficas entre populações.

O ciclo de vida dos insetos pode ser interrompido em qualquer fase do desenvolvimento (ovo, ninfa ou adulto), isso garante a sobrevivência desses insetos em condições desfavoráveis do ambiente (MANSINGH, 1971; S AUNDERS, 1976; DANKS, 1987). Segundo UVAROV (1966) as condições externas afetam a longevidade e o período de reprodução nos ortópteros.

De acordo com BeCK (1968), GULLAN \& CRONSTON (2000), Argolo et al. (2002), TRUdel et al. (2002) e
MACEDO et al. (2003) o fotoperíodo é um fator externo que, ao ser alterado, induz ou interrompe a diapausa, afeta o desenvolvimento e reprodução e a biologia de inúmeros grupos taxonômicos (Ordens) de insetos.

Já AMORIM \& ADIs (1995) citam que o fotoperíodo pode atuar como fator de controle (ecofator) no número de estádios ninfais de gafanhotos em ecossistemas tropicais, mesmo sendo situados perto do equador, devido a mudanças sazonais de insolação e/ou intensidade de luz durante o ano. Estudando o efeito do fotoperíodo em gafanhotos adultos TANAKA \& SODOYAMA (1997) observaram que os insetos submetidos a fotoperíodo curto realizaram posturas tardias contendo ovos inférteis. Pesquisas mostraram ainda que, gafanhotos adultos submetidos a essa condição mostram inativação das células neurossecretoras do cérebro, interferindo na dinâmica hormonal, afetando a mudança de ínstares e o amadurecimento do aparelho reprodutor (SAUNDERS, 1976; OKUDA \& TANAKA, 1996; ERGEN, 2001; SAUNDERS et al., 2004).

No entanto, não se tem relato da influência de diferentes fotoperíodos sobre aspectos histomorfométricos do aparelho reprodutor feminino de gafanhotos.

Assim, diante do exposto, a presente pesquisa teve por objetivo descrever histologicamente os principais órgãos do aparelho reprodutor feminino e realizar a morfometria dos ovários de T. collaris (Stoll, 1813), submetido a três fotoperíodos (10L, 12L e 14L).

\section{MATERIAL E MÉTODOS}

Insetos adultos foram coletados no Município de Pombos, Agreste de Pernambuco e levados para o Laboratório de Entomologia do Departamento de Biologia da UFRPE, sendo mantidos em gaiolas teladas, contendo recipiente para postura e alimentados com folhas de mangueira (Mangifera indica), trocadas a cada dois dias.

Para realização do experimento foram utilizadas 60 ninfas (30 machos e 30 fêmeas) no último estágio de desenvolvimento, sendo colocados 10 casais em gaiolas separadas e submetidos a três diferentes tratamentos:I: $10 \mathrm{~h}$ comluz/14h semluz;II:12h comluz/ 12h sem luz; III: $14 \mathrm{~h}$ com luz/10h sem luz.

A temperatura e umidade foram registradas por meio de termômetro de bulbo seco e bulbo úmido (higrômetro). Foram feitas 3 aferições diárias onde as médias obtidas para a temperatura e umidade relativa foram de $30 \pm 2^{\circ} \mathrm{C}$ e $72 \pm 10 \%$, respectivamente. 
Os fotoperíodos foram obtidos por meio de uma modificação da técnica preconizada por AMORIM \& ADIs (1995). Para isso, foi utilizada uma caixa de madeira, com dimensões de $180 \mathrm{~cm} \times 60 \mathrm{~cm} \times 120 \mathrm{~cm}$, dividida em 3 compartimentos, cada um contendo lâmpadas (modelo luz do dia, 40W) que forneceram cerca de 400 Lux na região ocupada pelos insetos. Dentro desta caixa foram colocadas as gaiolas teladas com os insetos, onde foram submetidos aos respectivos tratamentos. O controle da luminosidade foi realizado por meio de um timer. A limpeza das gaiolas e a troca da alimentação dos insetos foram realizadas sempre que necessário e no período de luz.

Trinta dias após atingirem o estágio adulto foram coletados os ovários (ovaríolos), ovidutos laterais, oviduto comum e receptáculo seminal (espermateca). Para isso os insetos foram sedados com éter etílico e dissecados sob estereomicroscópio.

A morfometria externa dos ovários equantificação dos ovaríolos foi realizada utilizando-se uma lupa binocular adaptada com uma ocular milimétrica, sendo registrado o comprimento e as larguras (láterolateral e dorso-ventral) dos ovários das fêmeas submetidas aos tratamentos. Em seguida foram separados e contados os ovaríolos.

A análise estatística foi realizada por meio da Análise de Variância (ANOVA) utilizando o Proc ANOVA do SAS.

Para análise histológica fragmentos dos órgãos coletados foram fixados em Boüin alcoólico empregandoa metodologia descrita por MichaLANY (1990)eprocessados parainclusãoem "paraplast". Posteriormente, os blocos foram cortados em micrótomo do tipo Minot ajustado para $5 \mu \mathrm{m}$. Os cortes assim obtidos foram submetidos às técnicas de colorações pela Hematoxilina - Eosina (H-E), tricrômico de Mallory e P.A.S. (Ácido Periódico de Schiff) empregando-se a metodologia descrita por BEHMERetal.(1976),J UNQUEIRA\&JUNQUEIRA (1983) e Michalany (1990). A análise morfológica foi realizada utilizando-se um microscópio de luz, e as lâminas fotografadas em fotomicroscópio.

\section{RESULTADOS E DISCUSSÃO}

Verificou-se a presença de dois tipos distintos de estágios de desenvolvimento ovariano em T. collaris. No primeiro estágio, os ovários apresentaram coloração amarelo-claro, dimensões reduzidas e ovaríolos poucos desenvolvidos (Prancha 1A). No segundo tipo, os ovários mostraram coloração amareloalaranjado, dimensões maiores que o primeiro tipo e ovaríolos desenvolvidos (Prancha 1B). O processo de maturação ovariana em gafanhoto pode ser dividido em quatro estágios: imaturo, pré-reprodutivo, reprodutivo e pós-ovulação. Segundo UvAROv (1966) alguns autores ainda destacam as cores: amarelo para os ovários pré-reprodutivos, e amareloalaranjado para os reprodutivos como fator classificatório. Nos resultados só foram evidenciados ovários pré-reprodutivos e reprodutivos em T. collaris.

A análisemorfométrica revelou queosfotoperíodos de 10L/14E, 12L/12E e 14L/10E, não afetaram o comprimento, largura látero-lateral e largura dorsoventral, tanto nos ovários pré-reprodutivos como nos reprodutivos, pois as médias não diferiram estatisticamente $(P>0,05)$ para todos os tratamentos (Tabela 1). No entanto, Velarde et al. (2002) estudando a influência do fotoperíodo sobreGalerucellacalmariensis L. (Coleoptera: Chrysomelidae) verificaram uma redução no tamanho do ovário quando adultos foram submetidos a um fotoperíodo curto.

Onúmero total deovaríolos, bem comoonúmerode ovaríolos no ovário esquerdo e direito em $T$. collaris, não diferiu estatisticamente $(P>0,05)$ entre os tratamentos (Tabela2).Éimportantemencionarqueessenúmerofoi sempre maior nos ovários esquerdo, independente do tratamento. O número de ovaríolos encontrado para essa espécie está de acordo com os relatos deCHAPMAN (1998) o qual cita que gafanhotos de pequeno porte têm comumente quatro ovaríolos em cada ovário enquanto que os maiores podem ter mais de 100. SegundoUvAROV (1966) o número de ovaríolos é uma ferramenta importante para estudos taxonômicos em gafanhotos, já que existe uma variação grande entre as famílias.

A análise histológica dos ovários, oviduto lateral, ovidutocomumeespermateca, deummodogeral,estáde acordo com as citações de vários autores(SNODGRASS, 1993; CHAPMAN, 1998; S ILVA \& CAETANO, 1991; B uZZI \& MIYAZAKI, 1999), indicando também que não houve interferência dos fotoperíodos sobre a morfologia desses órgãos.

Os ovários são em número de dois, apresentando cada um na região mediana e terminal, um oviduto lateral, que se converge para formar o oviduto comum. Estruturalmente, cada ovaríolo apresenta morfologia tubular, afilada no seu ápice, e três regiões bem características, as quais de acordo com VANETTI (1983), MELLO (1989), ElzINGA (1997), BuZZi \& MiYAZAKi (1999) e GARCiA \&GARCIA (2001) são denominadas: filamento terminal, germário e vitelário (Prancha 1C). O filamento terminal é constituído por um cordão de células que revelou sua natureza conjuntiva quando corado pelo tricrômico de Mallory. A função dessa estrutura é manter firme e em uma determinada posição o ovário na cavidade abdominal.Nogermárioascélulas germinativas primordiais ou ovogônias estão em intensa atividade mitótica e associadas às células foliculares (Prancha 1D). No vitelárioforamevidenciadoscompartimentoscontendo vários ovócitos em diferentes estágios de desenvolvimentos (Prancha1E). Nessa região, as células foliculares apresentam-secúbicas com núcleo oval ebasal apresentando atividade vitelogênica (Prancha 1F). 

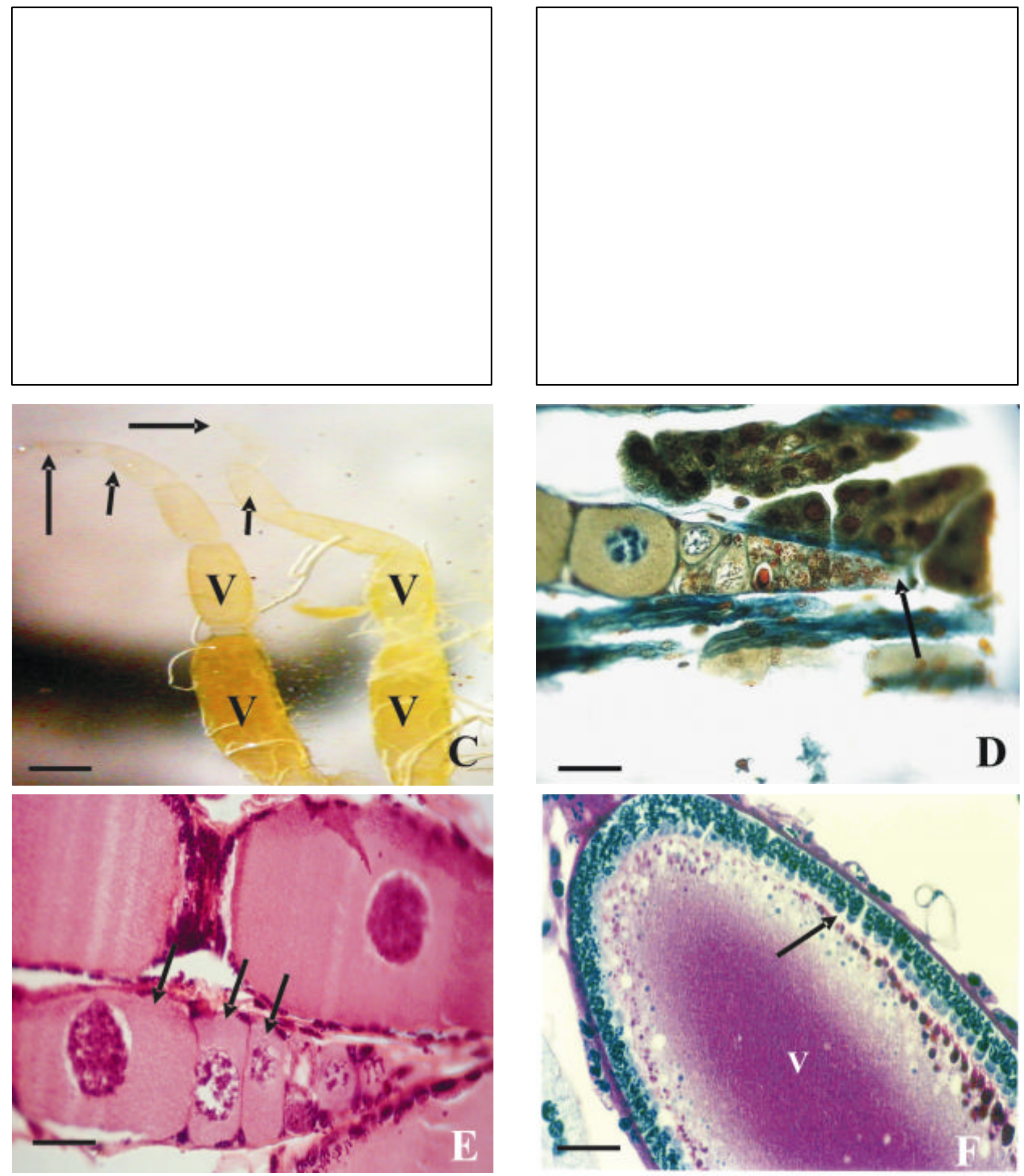

Prancha 1 - A - Ovário pré-reprodutivo de cor amarelo claro, dimensões reduzidas e ovaríolos pouco desenvolvidos. Barra $=500 \mu \mathrm{m}$. B- Ovário reprodutivo com ovaríolos bem desenvolvidos e coloração alaranjada. Barra $=500 \mu \mathrm{m}$. C Filamento terminal (setas longas), germário (setas curtas) e vitelário (V). Barra $=500 \mu \mathrm{m}$. D - Observar tecido conjuntivo constituindo o filamento terminal (seta). Tricrômico de Mallory. Barra $=100 \mu \mathrm{m}$. E - Vitelário com ovócitos em desenvolvimento com abundante citoplasma, núcleo esférico e central (setas). H.E. Barra =100 $\mu \mathrm{m}$. F-Observar natureza glicoprotéica do vitelo (V) secretado pelas células foliculares (seta). P.A.S. Barra $=25 \mu \mathrm{m}$.

O oviduto lateral é revestido internamente por uma camada de tecido epitelial simples cúbico com numerosas dobras, o qual está apoiado na membrana basal que o separa do tecido conjuntivo. Externamente esse órgão é revestido por uma camada de tecido muscular estriado (Prancha 2A e 2B). Porém, NELSEN (1934) e Silva \& CAETANo (1991) relataram que nos acridídeos o tecido epitelial que forma o revestimento interno do oviduto lateral é do tipo estratificado colunar, característico dessa família. 

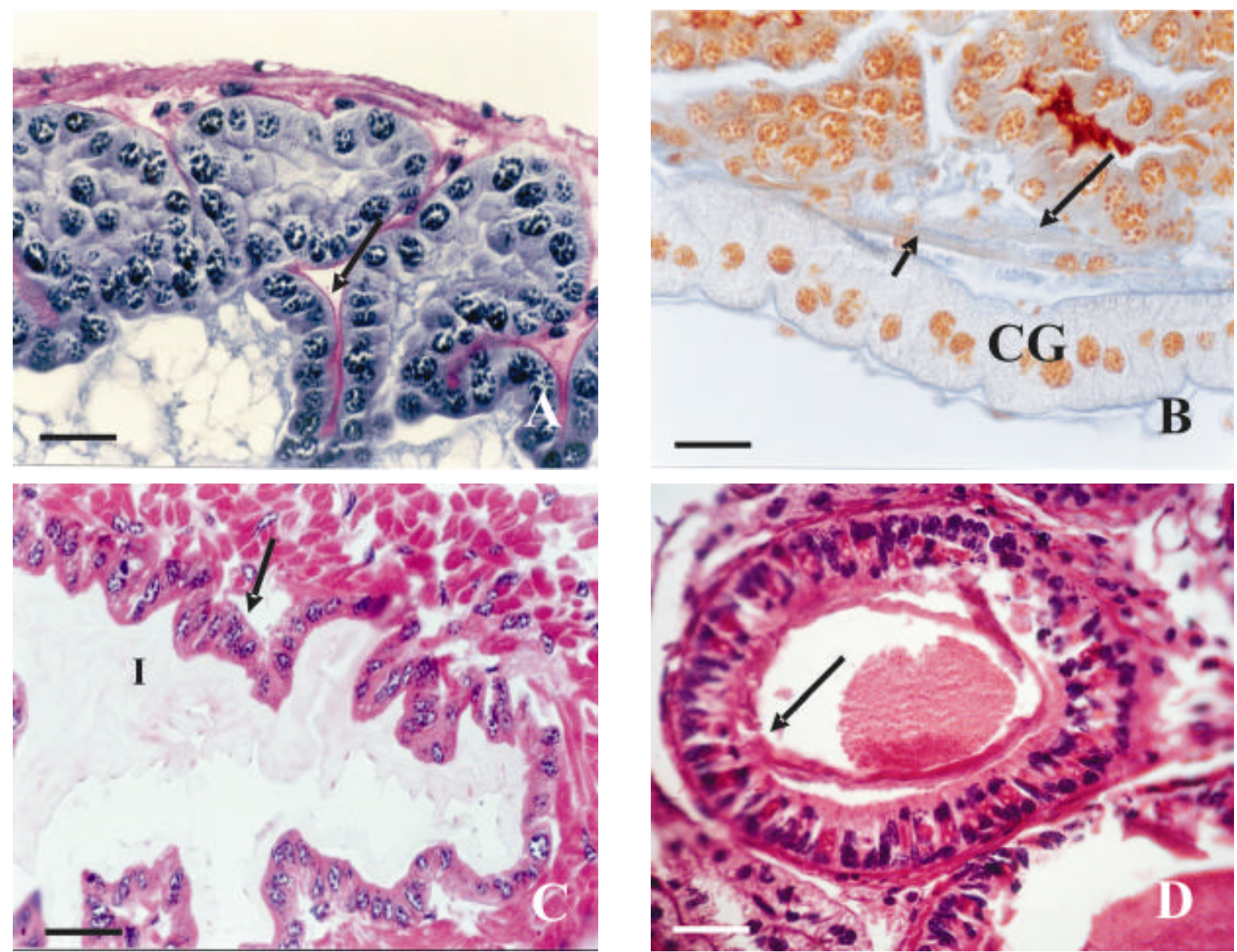

Prancha 2 - A - Oviduto lateral revestido por epitélio simples cúbico apoiado na membrana basal (seta). P.A.S. Barra $=25 \mu \mathrm{m}$. B - Observar no oviduto lateral delgada camada de tecido conjuntivo (seta longa) e tecido muscular disposto longitudinalmente (seta curta), além de corpo gorduroso associado na parede desse órgão(CG). Tricrômico de Mallory. Barra $=25 \mu \mathrm{m}$. C - Oviduto comum revestido por epitélio (seta) com espessa íntima (I). H.E. Barra $=100 \mu \mathrm{m}$. D Espermateca constituída por epitélio pseudo-estratificado colunar com íntima cuticular (seta longa) e tecido muscular estriado (seta curta). H.E. Barra $=100 \mu \mathrm{m}$.

O oviduto comum apresenta a mesma constituição histológica do oviduto lateral, entretanto verificou-se a presença de epitélio associado a uma espessa íntima cuticular e uma camada muscular bem desenvolvida (Prancha 2C). A presença dessa íntima de constituição quitinosa deve estar relacionada a sua origem, pois segundo RichaRDS \& DAVIES (1983) esse órgão forma-se pela invaginação da parede do corpo atrás do sétimo segmento abdominal. Já a desenvolvida camada muscular presente nessa região, a qual está ausente no tegumento, deve ter uma importante função durante a postura, ajudando a expelir os ovos.

Histologicamente a espermateca apresentou-se constituída por tecido epitelial pseudo-estratificado colunar recoberto por uma espessa íntima cuticular e logo abaixo observou-se duas camadas de tecido muscular estriado, uma longitudinal e outra circular, e entre elas tecido conjuntivo (Prancha 2D). SiLvA \& Caetano (1991) descrevendo a histologia da espermateca do gafanhoto Abracris flavolineata (Geer, 1773) (Orthoptera: Acrididae) relataram aspectos histológicos diferentes para essa espécie, pois o epitélio por eles descrito foi do tipo simples colunar e não verificaram a presença de tecido conjuntivo nesse órgão, provavelmente pela ausência de uma análise histoquímica.

\section{AGRADECIMENTOS}

A CAPES pela concessão de bolsa ao primeiro autor, possibilitando a realização deste trabalho.

REFERÊNCIAS

Amorim, M.A. \& Adis. J. Desenvolvimento ninfal do gafanhoto neotropical semi-aquático Stenacris fissicauda 
fissicauda (Bruner, 1908) (Orthoptera:Acrididae) em condições controladas. Acta Amazônica, v.25, p.73-92, 1995.

Argolo, V.M.; Bueno, V.H.P.; Silveira, L.C.P. Influência do fotoperíodo na reprodução e longividade de Orius insidiosus (Say) (Heteroptera: Anthocoridae). Neotropical Entomology, v.31, p.257-261, 2002.

BECK, S. D. Insect photoperidism. New York and London: Academic Press, 1968. p.134-207.

Behmer, O.A.; Tolosa, E.M.C.; Freitas Neto, A.G. Manual de técnicas para histologia normal e patológica. São Paulo: Edart, 1976.115p.

BILINSKI, S.M.; BÜNING, J.; SimicZYJEW, B. Neuropteroidea: different ovary structure in related groups. Folia Histochemica et Cytobiologica, v.36, p.189-195, 1998.

BuzZI, Z.J. \& MiYAZAKI, R. D. Entomologia Didática. 3.ed. Curitiba: Editora da UFPR, 1999. p.71-131.

Chagas, M.C.M.; Moreira, M.A.B.; Barreto, M.F.P. Biological aspects of Schistocercapallens, Stiphra robustaand Tropidacris collaris grasshoppers species at Rio Grande do Norte state, Brazil. Acta Horticulturae, v. 370, p.83-89, 1995.

CHAPMAN, R.F. The Insects: Structure and Function. London: Hodder and Stoughton, 1998. 770p.

Costa, M.K.C.M.Descrição histológica dos principais constituintes do aparelho digestivo do gafanhoto Tropidacris collaris (Stoll, 1813) (Orthoptera: Romaleidae). 2003, 38p. Monografia (Graduação em Licenciatura em Ciências Biológicas) - Universidade Federal Rural de Pernambuco, Recife, 2003.

D'ARAúJo,A.G.S.;G onçALVES, C.R. ; Galvão, D.M. Quartocatálogo dos insetos que vivem nas plantas do Brasil, seus parasitas e predadorese inimigos naturais , RiodeJaneiro: Laboratório Central de Patologia Vegetal, 1968. v.2, p.5.

DANKs, H.V. Insect dormancy: an ecological perspective. Ottawa: Biological Survey of Canada, 1987. 439p.

Duranton, J.F.; Launois, M.; Luong, H. L.; Lecog, M. Guia prático de luta contra os gafanhotos devastadores no Brasil. Roma: Fao-Cirad-Prifas, 1987. p.7-43.

ERGEN, G. The effects o precocene II on the fine structure of corpus allattum in adult female Anacridiumaegyptium L. (Orthoptera: Acrididae). Turk Journal Zoology, v.25, p.95-103, 2001.

ELzINGA, R.J. Fundamentals of entomology. 4. ed. New Jersey: Prentice - Hall, 1997. p.95-100.

Garcia, S.M.L. DE \& Garcia, C.F. Embriologia. 2.ed. Porto Alegre: Ed. Artmed, 2001. p.74-75.

Gullan, P.J.P. \& Gronston, P.S. The insects: an outline of entomology. 2.ed.Oxford: BlakwellScience, 2000.470p.

JAGLARZ,M.K.Thenumberthatcounts.Phylogeneticimplications of the number of nurse cells in ovarian follicles. Folia Histochemica et Cytobiologica, v.36, p.167-178, 1998.

JunqueIra, L.C.U. \& JunqueIRA, L.M.M.S. Técnicas básicas de citologia e histologia. São Paulo: Ed. Santos, 1983. p.50-75.

KubRAKIEWICZ,J.;J EDRZEJOWSKA,I;; B ILINSK, S. M. Neuropteroidea: different ovary structure in related groups. Folia Histochemica et Cytobiologica, v.36, p.179-187, 1998.

Lalitha, T.G.; Shyamasundari, K.; RaO, K.H. Morphology and histology of the female reproductive system of Abedus ovatus Stall(Belostomatidae:Hemiptera:Insecta). Memórias do Institu to Oswaldo Cruz, v.92, p.129-135, 1997.

Macedo, L.P.M.; Souza, B.; CarvalHo, C.F.; Escole, C.C. Influência do fotoperíodo no desenvolvimento e na repro- dução de Chrysoperla externa (Hangel) (Neuroptera: Chrysopidae). Neotropical Entomology,v.32, p.91-96,2003.

Mansingh, A.Physiological classification of dormancies in insects. Canadian Entomologist, v.103, p.983-1009, 1971.

Matsuda, R. Morphology and evolution of the insect abdomen. New York: Pergamon Press, 1976. p.534.

Mello, R.A. Embriologia comparada e humana. São Paulo: Atheneu, 1989. p.67-70.

Michalany, J. Técnica histológica em anatomia patológica. 2.ed. São Paulo: Ed. Michalany, 1990. p.126-144.

Nelsen, O.E. The development of the ovary in the grasshopper, Melanoplus differentialis (Acridae, Orthoptera). JournalofMorphology, v.55, p.515-543, 1934.

OKuDA, T. \& TANAKa, S. An Allatostatic factor and juvenile hormone synthesis by corpora allata in locusta.Journal Insect of Physiology, v.43, p.635-641, 1996.

Richards, O.W. \& Davies, R.G. Tratado de Entomología Imms. Estructura, Fisiología y Desarrollo. Barcelona: Ediciones Omega, 1983. p.304-336.

SAntos, E. Os insetos, vidas e costumes. Belo Horizonte: Itatiaia, 1982. v.1, p.47-49.

SAUnders, D.S. Seasonal cycles of development. In: 1976. p.73-83.

SAunders, D.S.; Lewis, R.D.; Warman, G.R. Photoperiodic inductuon of diapause: opening the black box. Physiological Entomology, v.29, p.1-15, 2004.

Silva, E.C.A. \& Caetano, F.H. Anatomia e histologia do aparelho reprodutor feminino de Abracrisflavolineata (Acrididae-Ommatolampinae-Abracrini). Boletim de Indústria Animal, v.48, p.23-29, 1991.

SimiczYJew, B.; OgorZaleK, A.;S TYS, P. Heteropteram ovaries: variations on the theme. Folia Histochemica et Cytobiologica, v.36, p.147-156, 1998.

SNODGRASS, R.E. Principles ofinsect morphology. 2.ed.London: Cornell University Press, 1993. p.567-573.

Szklarzewicz, T. The ovaries of scale insects (Hemiptera, Coccenea). Morphology and phylogenetic conclusions. Folia Histochemica et Cytobiologica, v.36, p.157-165, 1998.

TANAKA, S. \& SADOYAMA, Y. Photoperiodic termination of diapause in field-collected adults of the Bombay locust, Nomadacris succincta (Orthoptera: Acrididae) in southern Japan. Bulletin of Entomological Research, v.87, p.533-539, 1997.

Trudel, R.; Lavallée, R.; Bauce, É.; Guertin, C. The effect of cold temperature exposure and long-day photoperiod on the termination of the reproductive diapause of newly emerged female Pissodes strobe (Coleoptera: Curculionidae). Agricultural and Forest Entomology, v.4, p.301-308, 2002.

Uvarov, S.B. Grasshoppers and locusts. London: Cambridge University Press, 1966. p.138-144.

VAnetTI, F. Entomologia Geral. Belo Horizonte: Ed.Coopasul, 1983. p.256-260.

VelARDE, R.A.M.; WiEDENMANN, R.N.; VoegtuIN, D.J. Influence of photoperiod on the overwintering induction of Galerucella calmariense L. Bio Control,v.47, p.587-601,2002.

Recebido em 7/4/06

Aceito em 8/8/06 